\title{
Agente comunitário de saúde: sujeito da prática em saúde bucal em Alagoinhas, Bahia
}

\author{
Health community agent: \\ subject of the buccal health practice in Alagoinhas, Bahia State
}

Ana Áurea Alécio de Oliveira Rodrigues ${ }^{1}$

Adriano M aia dos Santos ${ }^{2}$

M arluce M aria Araújo Assis ${ }^{1}$

\footnotetext{
${ }^{1}$ Núcleo de Pesquisa Integrada em Saúde Coletiva, Departamento de Saúde, Universidade Estadual deFeira de Santana. Av. Transnordestina s/n, Novo Horizonte. 44036-900 Feira de Santana BA. aleccio@terra.com.br 2 Instituto M ultidisciplinar em Saúde. Universidade Federal da Bahia.
}

Abstract Thisstudy about the work of micro politics was carried out by the Buccal Health Team (ESB) in the Family Health Program (PSF) of Alagoinhas, Bahia State, and has as central theoretical purpose the specific and singular forms in the practice of daily work, using the technologies (hard, light-hard and light). The methodological trajectory is based on the historical-social current in view of a dialectic approach of qualitative nature. The techniques of data collection used were: semi structured interview, observation of the work process and documental analysis. The analysis of the data was oriented by the hermeneutics-dialectics, allowing to compare the different levels of analysis, articulating the theoretical with the empirical evidence. The results reveal that the Family Health Teams are multidisciplinary, but have still not developed an interdisciplinary work, hence occurring juxtaposition of skills. Each unit plans their work process according to the singularities of the social subjects, implementing different characteristics in how to welcome, inform, attend and refer. An effort in changing the work process can be perceived in the perspective of amplified clinic with the health community agent standing out as a social/collective subject.

Key words Community health agent, Family Health Program, Practices, Buccal health
Resumo Este estudo sobrea micropolítica do trabalho da Equipe deSaúdeBucal (ESB) no Programa deSaúdeda Família (PSF) deAlagoinhas(BA) toma por pressuposto teórico central as formas específicas e singulares no exercício do trabalho cotidiano, utilizando-sedastecnologias (duras, leveduras e leves). A trajetória metodológica é fundamentada na correntehistórico-social, à luz deuma abordagem dialética de natureza qualitativa. As técnicas de coleta de dados utilizadas foram entrevista semiestruturada; observação do processo de trabal ho eanálise documental. A análisedos dados foi orientada pela hermenêutica-dialética, permitindo confrontar os diferentes níveis de análise, articulando o teórico com o empírico. Os resultados revelam que as Equipes de Saúde da Família são multidisciplinares, mas ainda não desenvolvem um trabalho interdisciplinar, ocorrendo justaposição de saberes. Cada unidade planeja seu processo de trabalho de acordo com as singularidades dos sujeitos sociais, implementando características diferentes no acolher, informar, atender e encaminhar. Percebe-se um esforço em mudar 0 processo de trabalho, na perspectiva da clínica ampliada, com o agente comunitário de saúde se destacando como sujeito social/coletivo.

Palavras-chave Agente comunitário de saúde, Programa de Saúde da Família, Prática, Saúde bucal 
Introdução

$\mathrm{Na}$ organização do trabalho da saúde bucal, as atividades específicas dos vários profissionais envolvidos traduzem separações que permitem a distinção entre diversos graus de complexidade dos trabal hos parciais ou especializados, os quais requerem, também, diferentes graus de formação do trabalhador.

Temos, assim, que o processo de trabalho, também na saúde bucal, somente pode ser apreendido enquanto tal, se considerados, simultânea earticuladamente, todos os seus componentes. $E$, ainda, que um dado processo de trabal ho não ocorre isoladamente, mas sim numa rede de processos que se alimentam reciprocamente.

Ocorre, nessa rede, o encadeamento de distintos processos de trabal ho que se diferenciam pela sua peculiar conexão dos elementos constituintes (objeto, instrumentos, atividades) e se integram por meio das relações entre as necessidades que precisam internalizar para se realizar. Distintas áreas profissionais, cada qual realizando um processo de trabalho próprio, encontram nas necessidades de saúde seu ponto de confluência. Necessidades essas que se manifestam e são apreendidas desde diferentes ângulos ou aspectos, porém sempre referidas ao mesmo âmbito de carecimentos humanos, à mesma esfera da vida humana, à saúde.

N esse sentido é que os elementos constitutivos deum processo detrabalho searticulam através das relações sociais e técnicas, desenvolvidas através de práticasinstitucionais tecnologicamentedistintas, constituindo-seem atividades de saúde, linguisticamente mediadas, ou seja, de natureza também simbólica, atada, portanto, ao conjunto das práticas sociais², que irão determinar 0 modo como será realizado o trabalho, ou seja, 0 seu modo de produção.

As relações entre os sujeitos podem ser, de um lado, sumárias e burocráticas, em que a assistência se produz centrada no ato prescritivo, compondo um modelo que tem na sua natureza o saber médico hegemônico, produtor de procedimentos; por outro lado, podem se dar como relações "intercessoras", estabelecidas no trabaIho em ato, realizado no cuidado à saúde 3 .

Para M erhy e Franco ${ }^{4}$, esse trabalho é sempre relacional, dependendo do "trabalho vivo" em ato, isto é, o trabal ho no momento em que se está produzindo, ressaltando a importância das tecnologias leves como fundamental para a produção do cuidado.

As discussões na área de saúde e os projetos de intervenção dos vários grupos sociais interes- sados no setor têm destacado a necessidade de mudanças do modo de trabalhar na área, em todos os seus níveis de organização, não se devendo deixar de avaliar a situação macropolítica e a sua influência nos serviços. M as éimportante se dedicar à análise do espaço onde se dão as questões micropolíticas dos processos de trabaIho em saúde, na tentativa de procurar novas pistas para tratar as intenções de transformação que permeiam o setor saúde ${ }^{5}$.

Nesse espaço intercessor, os sujeitos em ação, indivíduos com singularidades e contextos diferentes passam a atuar como sujeitos que se interrelacionam e se complementam para a produção do cuidado, agindo, então, como atores que se articulam com criatividade no sujeito coletivo ${ }^{6}$.

0 trabalho das Equipes de Saúde Bucal no Programa de Saúde da Família busca romper a divisão especializada do trabalho e está voltado para a reorganização do modelo de atenção e para a ampliação do acesso às ações, com a proposta de garantir a atenção integral aos indivíduos e às famílias, mediante o estabelecimento de vínculo territorial? ${ }^{7}$.

A inserção das ações de saúde bucal no Programa de Saúde da Família, em 2001, teve, seguindo os princípios do SUS, a intenção de substituir as práticas tradicionais exercidas nas unidades de saúde. Desde então, muitas mudanças vêm ocorrendo no âmbito da saúde bucal coletiva; no entanto, ainda são evidentes os muitos problemas que precisam ser solucionados para vencer a iniquidade do acesso ao setor.

Peduzzi e Palma ${ }^{8}$ consideram que, na equipe multiprofissional, ocorre uma intersecção devariados objetos e instrumentos dispostos lado a lado, de modo fragmentário, deixando transparecer o rol deatividades de cada agente, bem como o conjunto deprocedimentos dos múltiplosagentes. Verifica-se uma mera justaposição de trabaIhos: cada parcela se apresenta como exercício autônomo e independente.

Consideramos, então, quenas equipes desaúde os profissionais atuam como "trabalhadores", em diferentes processos, com objetos próprios, saberes e instrumentos que conformam as especificidades ${ }^{6}$.

Essas relações, também nas Equipes de Saúde Bucal, não devem se limitar exclusivamente ao campo biológico ou ao trabalho técnico, devendo interagir com os outros profissionais, de forma a ampliar o seu conhecimento, permitindo a abordagem do indivíduo como um todo. A troca de saberes e o respeito mútuo às diferentes percepções precisa acontecer permanentemente entre todos os profissionais de saúde, para pos- 
sibilitar que aspectos da saúde bucal também sejam devidamente apropriados e se tornem objetos das suas práticas. A ESB deve ser - e se sentir - parte da equipe multiprofissional em unidades de saúde de qual quer nível de atenção"

Existe, nas equipes, um esforço em se realizar as ações de âmbito coletivo, com a participação de toda equipe do PSF, mas, ainda assim, as dificuldades são muitas. Os profissionais da ESF têm participado das ações mais gerais, em conjunto com as ESB, mas, quando se trata de questões mais específicas, não existe, real mente, um trabaIho interdisciplinar, o que não contribui para a apropriação da saúde bucal, por parte dos médiCOS, enfermeiros e demais trabalhadores, de forma que venha a se tornar objeto de suas práticas ${ }^{6}$.

$\mathrm{Na}$ ESB, a oferta de ações é o momento da intervenção tecnológica e assistencial propriamente dita, definida no consultório a partir da consulta odontológica, comandada e estruturada pelo saber do cirurgião-dentista que, na definição dos procedimentos a serem realizados, age como sujeito, executando escolhas e realizando vontades que não são exclusivamente técnicas, mas expressão de valores éticos e projetos ou interesses políticos, através da técnica ${ }^{10}$.

O trabalho assistencial em saúde sempre re quer alguma forma de autonomia dos agentes. Requer a tradução de normas gerais a casos particulares que devem ser considerados o mais próximo possível dessa singularidade. $N$ a sua dimensão operante, trata-se deintervenção técnica permeada por relações interpessoais, o que lhe atribui algum grau de incerteza intrínseca ${ }^{6}$.

$\mathrm{Na}$ análise do processo de trabalho das Equipes de Saúde Bucal (ESB), realizada em pesquisa de mestrado, no ano de 2004, no município de Alagoinhas (BA), um ator se destacou: 0 agente comunitário desaúde(ACS), sujeito com um agir singular, integrando comunidade e serviços de saúde, produzindo um território comum. O ACS atua como um sujeito que possibilita a comunicação entre os usuários e os trabalhadores de saúde, articulando escuta e fala, sendo um facilitador na criação do vínculo interpessoal ${ }^{11}$. Para N unes et al. ${ }^{12}$, o ACS tem se revelado 0 ator mais intrigante no que se refere à relação de trocas estabelecidas entre saberes populares de saúde e saberes médico-científicos, um elo cultural que potencializa o trabalho educativo, à medida que faz a ponte entre dois universos culturais distintos: o do saber científico e do saber popular.

0 trabalho dos agentes comunitários de saúde, inseridos nas Equipes de Saúde da Família, diferencia-se da prática dos demais componentes da equipe, na relação que estabelecem com a comunidade. No cotidiano de sua prática, assumem atividades que extrapolam as ações determinadas nas normas do M inistério da Saúde, evidenciando uma flexibilização das tarefas, na tentativa de dar respostas positivas às demandas da população. Dessa forma, acabam rompendo o enrijecimento da organização do trabalho, que se dá quando a divisão de tarefas é bem definida e cada trabal hador fica responsável pel o seu campo exclusivo de atuação. Neste sentido, "mais do que estar próximo da comunidade e da equipe de saúde, o agente comunitário pertence a esses dois territórios, podendo ser facilitador da criação de vínculos"11.

0 presenteartigo tem como objetivo analisar o papel do agente comunitário de saúde no cotidiano da Equipe de Saúde Bucal no Programa de Saúde da Família em Alagoinhas (BA), considerando a construção de saberes e práticas relacionadas ao campo da Saúde Coletiva.

\section{M etodologia}

O ptou-se por uma abordagem histórico-social e crítico-analítica pela possibilidade de conhecer os processos que delineiam os distintos padrões da relação entre Estado e sociedade, bem como as características dessa configuração no encaminhamento das propostas de mudança do setor saúde, o que permite responder a questões complexas nas suas distintas dimensões ${ }^{13,14}$.

Discute-se o processo de trabalho das Equipes de Saúde Bucal partindo da observação da prática e de entrevistas com trabal hadores de saúde, sustentando-se em M endes-Gonçal ves ${ }^{15} \mathrm{e}$ $M$ erhy ${ }^{5}$, pelo contraste entre aspectos objetivose subjetivos do processo de trabalho e as concepções desses agentes a respeito do mesmo e das diversas questões a ele conexas.

A relação dos sujeitos envolvidos na produção do serviço de saúde foi analisada a partir da prática da Equipe de Saúde Bucal inserida na Unidade de Saúde da Família, articulada com os princípios teóricos quenorteiam as ações na área de saúde bucal, realizando confronto entre os dados empíricos (entrevista e observação) e a análise de documentos.

A investigação foi realizada no sistema desaúde de Alagoinhas (BA), município localizado a 107 quilômetros de Salvador, com uma população estimada de 138.366 habitantes $^{16}$. A escolha do município foi intencional, pois já existia um serviço relativamenteestruturado, com a implantação das Equipes de Saúde Bucal, no PSF, desde 2001. 
No recorte temporal da pesquisa, o município possuía 21 Equipes de Saúde da Família, responsáveis, aproximadamente, por $52 \%$ de cobertura da população, oferecendo serviços mé dicos, de enfermagem e de saúde bucal. As Equipes de Saúde Bucal eram compostas por um cirurgião-dentista e um auxiliar de consultório dentário ( $A C D$ ), trabal hando em conjunto com médicos, enfermeiros, técnicos de enfermagem e ACS (equipemínima), na proporção deuma ESB para cada duas equipes do PSF.

Os instrumentos de coleta de dados utilizadosforam entrevista semiestruturada, por setratar de uma forma privilegiada de coleta de informações para as ciências sociais, oferecendo a possibilidade da fala ser reveladora de condições estruturais, de sistemas de valores, normas e símbolos e, ao mesmo tempo, ter a magia de transmitir, através de um porta-voz, as representações de grupos determinados, em condições históricas, socioeconômicas e culturais específicas ${ }^{14}$; observação do processo de trabalho, estratégia essencial no trabal ho de campo da pesquisa qualitativa, processo pelo qual se mantém a presença do observador numa situação social, com a finalidade de real izar uma investigação científica, sendo o observador parte do contexto sob observação, que ao mesmo tempo modifica e é modificado por esse contexto ${ }^{14}$, e análise documental, utilizada de forma complementar.

Formularam-se roteiros temáticos utilizados na condução das entrevistas e da observação da prática, tendo como eixo condutor três questionamentos centrais: (1) quais as práticas, individuais e coletivas, desenvolvidas pelos ACS; (2) como se dava a articulação entre os ACS, a equipe de saúde bucal e os usuários; (3) quais os instrumentos de trabalho e qual o significado do trabalho em saúde bucal para ACS.

Os sujeitos participantes da pesquisa foram os cirurgiões-dentistas, os auxiliares de consultório dentário e os agentes comunitários de saúde, contemplados em onze entrevistas, e observados em quatro diferentes USF.

Para a análise do material empírico, inspirou-se na proposta da hermenêutica-dialética, baseando-se em M inayo ${ }^{14}$, cujo objeto de análise é a práxis social, e o sentido que se busca é a afirmação ético-política do pensamento e, ainda, segundo Assis ${ }^{17}$, possibilita o encontro da especificidade do objeto, pela prova do vivido, com as relações essenciais que são estabelecidas nas condiç̧̃es reais e na ação particular e social. A análise de um contexto histórico-estrutural específico exige um movimento contínuo entre os dados empíricos eo referencial teórico eleito pelo pesquisador.

$\mathrm{Na}$ transcrição das gravações, manteve-se a informação coletada, na forma usada pelo interlocutor, mesmo em desacordo com a norma (gramatical) oficial, respeitando-seos vícios delinguagem, as pausas, ou seja, a maneira peculiar que cada indivíduo tem de se expressão oralmente.

Seguiu-se a Resolução n 196, do Conselho Nacional de Saúde ${ }^{18}$, ea coleta dos dados foi submetida à apreciação do Comitê de Ética em Pesquisa da Universidade Estadual de Feira de Santana, que em reunião plenária do dia 16 de dezembro de 2003 considerou pertinentes o projeto eos termos de consentimento livreeesclarecido (TCLE) que deveriam ser assinados por todos os sujeitos da investigação.

Agente comunitário de saúde: práticas, articulações e instrumentos

Nas entrevistas e nas observações da prática, os agentes comunitários de saúde demonstram-se com bom nível de conhecimento em relação às necessidades da população, inclusive no campo da saúde bucal. N esse sentido, a implantação das Equipes de Saúde da Família, a princípio composta por médico, enfermeira etécnico em enfermagem, que, em 2000, passou a incorporar trabalhadores de saúde bucal, amplia o processo de trabalho do ACS, pois esse deixa de atuar sozinho, passando a interagir com uma equipe multiprofissional ${ }^{19,20}$.

O PSF, também, possibilitou avanços naatenção à saúde bucal, pois permitiu a ampliação do cuidado, incorporando novas práticas e novos sujeitos, impingindo novas articulações e novos instrumentos no processo de trabalho, orientados pelo dispositivo do acolhimento ${ }^{21}$.

Os trabalhadores, durante a pesquisa empírica, ao tratar das mudanças que ocorreram no município, após implantação das ESB, manifestam de forma convergente que houve melhorias eganho em resolubilidade. Tal fato éassim sintetizado: Q uando a gente trabalhava com o PACS, a gente só fazia mesmo a parte de pal estra, deeducação, porque não tinha pra onde mandar esses pacientes. Pra comunidade foi maravilhoso e pra gente também. Porqueaqui na comunidadeas pessoasjá tinham os problemas dentários, então a gente, só dizer a ele que escove, quetem que escovar o dente, quetem quefazer isso aquilo, não ia adiantar nada. Também tinha que dar o tratamento. Porque a gente cansava de chegar nos domicílios e via gente 
com dente infeccionado, com dor de dente e não tinha pra onde encaminhar. Isso era um constrangimento pra gente etambém pro paciente. (Entrevista 6, Grupo I)

O ACS reporta-se aos limites das ações de educação em saúde, ressaltando a importância da clínica no atendimento das necessidades da população, ou seja, recupera, na afirmação, a necessidade de condutasterapêuticas integrais, uma vez que as necessidades odontológicas estão historicamente constituídas e representadas nas demandas da comunidade e necessitam de diferentes tecnologias de trabal ho para que se consubstanciem em práticas resolutivas e socialmente legítimas.

Contudo, Santos ${ }^{22}$ alerta que tais conquistas dependem deformas comprometidas de compreensão do próprio processo de trabalho em saúde e utilização de dispositivos relacionais (acolhimento, vínculo) e dispositivos instituintes (autonomia, pertencimento, empoderamento) para transformar o complexo mundo de necessidades odontológicas, além do desenvolvimento de uma ética profissional pautada no compromisso com o produto (intervenção), com a comunidade (sujeitos) e com o Sistema Ú nico de Saúde - SU S (gestão, modelo, instituição).

Outro depoente concorda com o ponto de vista citado e destaca a importância da atuação da ESB para a mudança da condição de saúde da população: Considero queo trabalho desaúdebucal teve uma grande mudança, pois antigamente via 0 problema, mas não sabia nem identificar. E quando identificava, não tinha para ondemandar. Existia uma demanda que se aventurava a uma vaga com o dentista. (Entrevista 8, Grupo I)

Aqui, duas considerações de relevância ficam evidentes: a primeira traz a necessidade do conhecimento para identificar os problemas em saúde bucal; a segunda, a importância da ESB para promover 0 atendimento à demanda.

Além da mudança trazida com a ESB em relação à possibilidade da integralidade, encontramos também, no discurso de um cirurgião-dentista, destaque para a importância da experiência prévia dos agentes comunitários do PACS como facilitador das ações implantadas com o PSF: Quando a gente chegou aqui com o PSF, já existiam os agentes comunitários queeram do PACS. Aí, então, ficou mais fácil. 0 pessoal já tinha noção, justamente, do trabalho preventivo e educativo na comunidade. (Entrevista 9, Grupo I)

Em 1997, o Ministério da Saúde, através da Portaria n $1886 /$ GM $^{23}$, reconhece no PACS e no PSF importantes estratégias para contribuir ao aprimoramento e consolidação do Sistema Ú nico de Saúde, aprovando as normas e diretrizes para os dois programas, estabelecendo, também, os critérios para seleção do ACS: ter no mínimo dezoito anos de idade, morar há mais de dois anos na comunidade, saber ler e escrever e ter disponibilidade de tempo integral para exercer suas atividades.

A exigência do M inistério da Saúde de que o ACS resida na comunidade onde irá trabalhar tem a intenção de que ele desenvolva uma integração entre a equipe de saúde e a comunidade. Para Silva et al. ${ }^{11}$, o fato deser al guém quevivencia a realidade da comunidade equetrabalha a partir de referenciais biomédicos com as práticas de saúde do bairro ondemora faz deleum sujeito quetraz consigo uma série de contradições. A o mesmo tempo, possi bilita a construção de vínculos, de reorganização do trabalho da equipe de saúde, de ampliação do acesso ao serviço e da atuação como facilitador da comunicação entre comunidade e profissionais de saúde.

O M inistério da Saúdereconheceo PSF como estratégia prioritária para consolidação da atenção básica, através da Portaria n 648 , de 28 de março de 2006 eatual iza as atribuições comunse específicas dos diversos componentes da equipe de saúde da família. N este documento, ao ACS cabe, além de outras, desenvolver atividades de promoção da saúde, de prevenção das doenças e de agravos, edevi gilância à saúde, por meio devisitas domiciliares e de ações educativas individuais e coletivas nos domićlios e na comunidade, mantendo a equipe informada, principalmente a respeito daquelas em situação de risco24.

Para M ishima e Campos ${ }^{25}$, é importante ressaltar que, mesmo sendo de responsabilidade de toda a equipea articulação com indivíduos, família e comunidade, cabe aos ACS o esforço inicial de articulação e integração e, ainda, o estabel ecimento devínculos com a comunidade. Assumem, assim, um papel relevante no desencadeamento de ações que se caracterizam por uma perspectiva de atendimento integral, incorporando a preocupação em aumentar a capacidade de autonomia da comunidade e das famílias atendidas.

Em vários municípios da Bahia, as ações de saúde bucal, desenvolvidas pelos ACS, incluem palestras educativas sobre higiene bucal em domicílios e escolas, realização de bochechos fluoretados e, em algumas localidades, a aplicação tópica de flúor em escolares ${ }^{24}$. No município em estudo, percebe-se que as atividades relacionadas pelos agentes estão de acordo com o preconizado pelo M inistério da Saúde: Agente comu- 
nitário de saúdeé saúde da criança, évisita domiciliar todos os dias, acompanhamento às gestantes, desenvolvimento da criança, peso, é, doença, infecção, diarréia, saúde, escovação. A gentefaz com a dentista. A companhamento do idoso, hipertensão e diabetes. Acompanhamento da gestante até os nove meses da gestação. $\mathrm{E}$ o trabal ho da dengue, a orientação na limpeza dos quintais do povo. (Entrevista 2, Grupo I).

Assim, as ações abrangem diversos níveis de complexidade, inclusive das vigilâncias sanitária e epidemiológica. No entanto, há uma forte predominância de ações organizadas para grupos, como crianças, hipertensos, diabéticos, gestantes e idosos, semelhante à proposta das ações programáticas. Prática que se repete em outras regiões do país, como mostra o estudo de Levy, $M$ atose Tomita ${ }^{26}$, realizado em um município de São Paulo, onde as ações de saúde bucal eram mais voltadas para gestantes e crianças.

Com relação à realização de atividades coletivas em saúde bucal, os trabalhadores relatam que a escovação, a pal estra e a aplicação de flúor são realizadas pelos ACS, com o acompanhamento do cirurgião-dentista. Outros dizem que - ACS atua sozinho: No início do PSF, eu ia pra todas as escovações, fazia palestras. Aí, quando foi ano passado, a gentefez uma capacitação dosagentes comunitários. Inclusive, a gente deu certificados pra eles. Foi um dia todo discutindo saúde bucal, fazendo exercício. Eles receberam certificados ehojeeles vão fazer sem a minha presença. (Entrevista 3, Grupo I)

Deacordo com as Diretrizes da Política Nacional de Saúde Bucal ${ }^{9}$, considerando a importância dequeo trabalho do $C D$ não serestrinja apenas a sua atuação no âmbito da assistência odontológica, limitando-se exclusivamente à clínica, suge re se cautela no deslocamento frequente deste profi ssi onal, para a execução das ações coletivas. Estas devem ser feitas, preferencialmente, pelo THD, pelo ACD epelo ACS.

Observamos que o ACS se constitui efetivamente em um membro da equipe de saúde bucal e se destaca em seu processo de trabalho, atuando como sujeito, influenciando as ações internas eexternas daUSF, tornando-se determinantepara a articulação das equipes com a comunidade, sendo, ao mesmo tempo, um agente institucional e comunitário. Segundo Silva e Dalmaso ${ }^{27}$, essas categorias aparecem como duas expressões indissociáveis da prática, de dimensões de transformação social, de compromisso de ética e de solidariedade, não sendo excludentes ou antagônicas, mas sim indissociáveis e complementares.
$\mathrm{N}$ a rede de relações estabelecida no processo de trabalho nas ESF, o ACS tem clareza de sua importância como sujeito coletivo e do seu valor junto ao serviço $0^{6,22}$, como identificamos na fala deuma agente, sobre sua participação nas reuniões da ESF: Claro, sempre estou presente. Sem a gente trazer 0 que a população quer não tem 0 trabalho correto. (Entrevista 2, Grupo I)

$\mathrm{N}$ as observações, constatou-se que os agentes comunitários participam do diagnóstico de grupos socialmente vulneráveis, orientando as práticas das equipes no processo de planejamento das ações da USF, destacando a importância da identificação das carências para se planejar as ações junto a ESB. A fala seguinte traduz a análise: A gente olha a necessidade das crianças. Se a gente vê que tem um grande número de cárie, aí a gente conversa com a dentista. Aí ela faz uma orientação. Às vezesa gentevai mensalmente, às vezes a gente vai bimestral, e às vezes, dependendo da necessidade das crianças, aí a gente faz um trabaIho de acordo com a necessidade das crianças, do estado queeles estão, queos dentes del es estão. (Entrevista 6, Grupo I)

Agente comunitário de saúde: empoderamento e alteridade

No cotidiano das práticas, fica evidente a capacidade dos ACS em conduzir as ações ea clareza dos mesmos sobreo objeto detrabalho, principalmente no que está relacionado com as atividades de educação em saúde. Tal destaque foi observado durante uma atividade de sala de espera desenvolvida pelo entrevistado 6, do grupo I, que ao abordar temas de saúde bucal, discutiu desde técnicas de higiene bucal atéidentificação de lesões cancerizáveis, o que corroborou sua entrevista, a respeito de suas atribuições: A saúde bucal a gente trabalha assim, fazendo palestras nas escolas. Faz acompanhamento com as crianças nas escolas. Além de a gente trabalhar com criança, a gente trabalha também com adultos. $\mathrm{Na}$ parte de quem usa prótese, a gentefaz um exame, eseelesfazem o exame, 0 autoexameem casa, e orienta também, se aparecer alguma lesão a gente fala quais são as lesões que deve prestar atenção. E aí a gente orienta pra vim pro posto pra poder ser encaminhado pra Feira de Santana. E trabalha também em geral.

A desenvoltura em abordar os temas de saúde bucal deve-se ao processo de educação permanente, por meio de atividades realizadas pela coordenação municipal de saúde bucal e pelos cirurgiões-dentistas das USF, que durante o pro- 
cesso de trabalho, nas próprias unidades de saúde, orientam os agentes e os demais membros da ESF sobre diversos temas relacionados com 0 cuidado e atenção à saúde bucal. Situação que difere de resultados encontrados em outros estudos como o de Levy, Matos e Tomita ${ }^{26} \mathrm{e} o$ de Ferraz e Aerts ${ }^{28}$, realizados em municípios de São Paulo e do Rio Grande do Sul, respectivamente, pesquisas que abordam a ausência e a necessidade da capacitação do ACS acerca de saúde bucal.

Considera-se, frente aos dados empíricos coletados, que esse processo de educação permanente em saúde tem possibilitado a agregação entre aprendizado, reflexão crítica sobre 0 trabal ho, resolubilidade da clínica e a promoção da saúde coletiva, como pode ser visto nas convergências a seguir: Q uando a gente vai pra escola fazer a palestra, aí o dentista vai com a gente. Ela manda que a gente mesmo faça avaliação da criança. Aí a gente abre a boca da criança, vê como é que tá, se é uma coisa que já tá no dia a dia da rotina, a gente só faz anotar, se não a gente chama. Aí ela explica a gente direitinho: - Isso aqui é assim, assim, na próxima vez que você pegar com isso, você já sabe. (Entrevista 6, Grupo I)

Com relação aos agentes comunitários, eles foram capacitados, todos são capacitados, principalmente no âmbito da odontologia, tanto para dar palestras como pra fazer a escovação, aplicação de flúor e já têm essa capacitação e, por sinal, têm trabalhado super bem. Eles sabem realmente passar pras crianças e pras pessoas as informações. Eles também são capacitados pra detecção de câncer bucal. (Entrevista 5, Grupo I)

Com relação à capacitação dos ACS em Alagoinhas, destaca-se 0 trabalho de educação na área de câncer bucal. Deacordo com Araújo ${ }^{29}$, em 1998 foi iniciado o processo de educação sobre prevenção do câncer bucal através da capacitação de 99 ACS, o que tem permitido a difusão de atividades preventivas, de orientação sobre 0 autoe xame paraidentificar lesões, como também o rastreamento de lesões cancerizáveis pelos próprios agentes. A proposta, então, era que as capacitações deveriam ocorrer com periodicidade de seis meses, devendo também abordar temas pertinentes à prevenção de cárie e doença periodontal ${ }^{25}$.

Acredita-se que, dessa forma, o município aproxima-se do conceito de empoderamento, pois reforça a capacidade do ACS de ser um agente cuidador, dotado deconhecimento técnico privilegiado, reforçada pela condição singular de ser parteda comunidadequeécuidada. Com tal atitude, a ESB amplia-se, possibilitando ações mais efetivas e eficientes, baseadas no vínculo.
Ainda analisando as atividades desenvolvidas pela ESB, identificou-se forte influência dos agentes na marcação de consulta; como está explícito na fala abaixo, existem unidades em que os ACS se responsabilizam pela seleção dos usuários que "necessitam" de tratamento, não identificando área de risco, mas sim indivíduos que são encaminhados para atendimento: $E$ então como a gente tem procedido? A gente tem dado um turno para cada agente comunitário. Sendo que cada agente tá tendo em torno de oito vagas. $\mathrm{E}$ aí eles mesmos estão marcando. Porque lá a genteteria em torno de nove mil pessoas. Como a gente resselecionar? Então aí tá indo só pela indicação do agente. $\mathrm{N}$ o caso aquel es que estão mais necessitados "vírgula", porquetodos tão necessitados. (Entrevista 5, Grupo I)

Embora as atividades internas da USF não sejam atribuições diretas do ACS, existem situações em que 0 agente tem desempenhado função que não Ihe cabe realizar, como 0 agendamento das consultas; a fala seguinte explicita tal fato: Tanto que teve um problema agora na marcação, porque o ACS ficou nessa responsabilidade, quenão é função dele fazer a marcação. $E$ aí teve uma confusão lá na comunidade, porque ela distribuiu as fichas seis horas da manhã. (Entrevista 3, Grupo I)

Tal dinâmica gera al guns conflitos, poiso vínculo do ACS com a comunidade tem levado, em algumas situações, à tentativa de determinar quem deve ou não ser atendido pela ESB. $\mathrm{Na}$ fala de um cirurgião-dentista que estava há apenas cinco meses na unidade, conseguimos perceber tal situação: Além disso, é cobrança por parte das agentes comunitárias, de que deve se atender ou não deve se atender. Claro que uma das unidades tem uma quantidade bem maior. Essa cobrança nunca foi me levada de forma direta, mas a gente entende entre linhas. (Entrevista 11, Grupo I)

Essa atitude pode ser uma forma de gerar privilégios, em que as pessoas mais próximas e afins ao ACS seriam beneficiadas em detrimento de outras $5^{6,21,27}$.

A participação comunitária é compreendida como principal catalisador das ações comuns, constituindo a possibilidade do sujeito-usuário influenciar o planejamento e a dinâmica de funcionamento do serviço de saúdejunto a gestores e equipedesaúde, por meio deórgãos específicos como o Conselho de Saúde, ou simplesmente participando de reuniões no próprio posto, para definir seu funcionamento ${ }^{11}$.

$\mathrm{Na}$ questão de incentivo ao controle social por parte dos usuários, embora as falas não explicitem claramente a questão, podemos perce- 
ber essa contribuição quando relatadas as reuniões para discutir problemas da unidade, como, por exemplo, a marcação de consulta. A própria atuação no dia a dia da comunidade contribui para aumentar a sensi bilidade da população sobre o processo saúde-doença, seus determinantes e a importância da participação da comunidade para melhoria da situação. A fala a seguir sinaliza essa possi bilidade de alteridade nas práticas de saúde bucal: Eu fazia maiso trabalho preventivo, engraçado que o pessoal da comunidade não conhecia o trabalho do PSF, ninguém sabia falar, às vezes via na televisão. Ah, aquele programa de saúde da federal. Então a gente fazia reunião, às vezes na própria casa do paciente mesmo, explicava como era o trabalho que ia ser desenvolvido, o que era que o médico ia fazer, o que era que 0 enfermeiro, que é que o dentista ia fazer. Apresentar a proposta do PSF, então era todo essetrabaIho desenvolvido. (Entrevista 9, Grupo I)

Outro aspecto relevante constatado na pesquisa foi a organização dos ACS enquanto categoria, que participa ativamente dosfóruns de saúde municipais - como observado na $1^{a}$ Conferência Municipal de Saúde Bucal ocorrida em maio de 2004, que contou com a participação dos ACS em rodas de discussão e na plenária final, defendendo propostas demaneira colegiada. Esse momentos são, particularmente, importante pois por não ser meramente um arranjo gerencial, Ihe cabe cartografar a realidade a que se referee operar processos pedagógicos de ordenamento da rede de atenção, de permeabilidade às práticas populares, de qualificação das práticas pela integralidade da atenção e de produção de apren dizagens significati- vas, pela alteridade com as pessoas, histórias devida e histórias culturais que buscam as ações, os serviços e os sistemas de saúde. A roda serve para alimentar circuitos de troca, mediar aprendizagens recíprocas e/ou associar competências. É por estarem em roda que os parceiros criam possibilidades à realidade, recriam a realidade e/ou inventam realidades segundo a ética da vida quese anuncia nas bases em que são geradas ${ }^{30}$.

No âmbito nacional, após vários anos de discussão sobre suas atribuições e características profissionais, foi criada a profissão dos agentes comunitários de saúde, através da Lei n 10.507, de 10 dejulho de 2002.

\section{Consideraçõesfinais}

As situações relatadas acima demonstram que 0 ACS, em Alagoinhas, tem sido um ator fundamental para a mudança do modelo de atenção. Apesar de, no seu processo de trabalho, assumir al gumas atribuiç̧̃̃es que não são de sua responsabilidade, sua ação comunitária, deâmbito coletivo, integrando a promoção da saúde com a clínica, contribui para quebra do modelo hegemônico, que tem no centro o profissional médico el ou o cirurgião-dentista. O ACS, junto à ESB, tem contribuído para uma nova forma de se produzir cuidado em saúde bucal, a partir do acompanhamento simbiôntico da comunidade, produzindo zonas de encontro em que às subjetividades do outro são incorporadas na dinâmica terapêutica, por meio da significação dos valores sobre a vida, sobre a pessoa humana e a arte da alteridade.

\section{Colaboradores}

AAAO Rodrigues eM M A Assis realizaram a pesquisa empírica que resultou no artigo. AM Santos colaborou na redação do artigo. 
Referências

1. Peduzzi M. Equipe multiprofissional de saúde: a interface entre trabalho e interação [tese]. Campinas (SP): Faculdade de Ciências M édicas, Universidade de Campinas; 1998.

2. Silveira TCC. Processo de trabalho em saúde. Rev Saúde Coletiva da UEFS 2002; 1:121-127.

3. M erhy EE. Saúde: a cartografia do trabalho vivo. São Paulo: Hucitec; 2002.

4. M erhy EE, Franco TB. Por uma composição técnica do trabalho em saúde centrada no campo relacional e nas tecnologias leves. Apontando mudanças para os modelos tecno-assistenciais. Saúde em Debate 2003; 27(Supl. 65):316-323.

5. M erhy EE. O SUS e um dos seus dilemas: mudar a gestão e a lógica do processo de trabalho em saúde (um ensaio sobre a micropolítica do trabalho vivo). In: Fleury S, organizador. Saúde e democracia: a luta do CEBES. São Paulo: Lemos; 1997. p.125-141.

6. Rodrigues AAAO, Assis M M A. Construção de sujeitos, saberes e práticas na saúde bucal de Alagoinhas Bahia: o trabalho cotidiano no programa de saúde da família como protagonista da mudança [dissertação]. Feira de Santana (BA): U niversidade Estadual de Feira de Santana; 2005.

7. Brasil. Portaria no 1.444. Estabelece incentivo financeiro para a reorganização da atenção prestada nos municípios por meio do programa de saúde da família. Diário Oficial União 2000; 29 dez.

8. Peduzzi M, Palma JJL. A equipe de Saúde. In: Schraiber LB, Nemes MIB, M endes-Gonçalves RB, organizadores. Saúde do adulto: programas e ações na unidade básica. São Paulo: Hucitec; 2000. p. 234-250.

9. Brasil. Ministério da Saúde. Diretrizes da política nacional de saúde bucal. Brasília: Ministério da Saúde; 2004.

10. Schraiber LB. Pesquisa qualitativa em saúde: reflexões metodológicas do relato oral e produção de narrativas um estudo sobre a profissão médica. Rev. Saude Publica 1995; 29(Supl. 1):63-74.

11. Silva RVB, Stelet BP, Pinheiro R, Guizardi FL. Do elo ao laço: o agente comunitário na construção da integralidade em saúde. In: Pinheiro R, M attos RA, organizadores. Cuidado: as fronteiras da integralidade. Rio de Janeiro: IMS/UERJ, Abrasco; São Paulo: Hucitec; 2004. p. 75-90.

12. Nunes M O, Trad LB, Almeida BA, Homem CR, M elo M CIC. $O$ agente comunitário de saúde: construção da identidade desse personagem híbrido e polifônico. Cad Saude Publica 2002; 18(Supl. 6):1639- 1646

13. Triviños ANS. Introdução à pesquisa social em ciências sociais: a pesquisa qualitativa em educação. São Paulo: Atlas; 1992.

14. M inayo M CS. 0 desafio do conhecimento: pesquisa qualitativa em saúde. 6ª ed. São Paulo: Hucitec; Rio de Janeiro: Abrasco; 1999.

15. M endes-Gonçalves RB. Tecnologia e organização social das práticas de saúde. São Paulo: H ucitec; 1994.

16. Instituto Brasileiro de Geografia e Estatística. Pesquisa nacional por amostra de domicílios (PNAD). Rio de Janeiro: IBGE; 1998.

17. Assis M M A. M étodo de análise em pesquisa qualitativa em saúde. Feira de Santana: UEFS; 2003.
18. Brasil. Resolução n 196/96 do Conselho Nacional de Saúde. Ministério da Saúde. Diretrizes e normas regulamentadoras de pesquisa envolvendo seres humanos. Diário Oficial da União 1996; 16 out.

19. Brasil. Portaria no 267/GM, de 6 de março de 2001. Reorganização das ações de saúde bucal na atenção básica. Diário O ficial da União 2001; 7 mar.

20. Coelho CMA, Andrade LOM. Impacto provocado pela implantação do Programa Saúde da Família sobre as ações dos agentes comunitários de saúde o caso de Sobral/CE. SANARE 2004; 5(1):159-167.

21. Santos AM, Assis M M A, Rodrigues AAAO, Nascimento MAA, Jorge MSB. Linhas de tensões no processo de acolhimento das equipes de saúde bucal do Programa Saúde da Família: 0 caso de Alagoinhas, Bahia, Brasil. Cad Saude Publica 2007; 23(1):75-85.

22. Santos AM. Organização das ações em saúde bucal na estratégia de saúde da família: ações individuais e coletivas baseadas em dispositivos relacionais e instituintes. Rev Atenção Primária à Saúde 2006, 9(2):190-200.

23. Brasil. Portaria no $1.886 / G M$ de 18 de dezembro de 1997. Normas e Diretrizes do Programa de ACS e do PSF. Aprova as normas e diretrizes do Programa de Agentes Comunitários e do Programa de Saúde da Família. Diário Oficial da União 1997; 22 dez.

24. Brasil. Portaria n ${ }^{\circ} 648$, de 28 de março de 2006. Aprova a Política Nacional de Atenção Básica, estabelecendo a revisão de diretrizes e normas para a organização da Atenção Básica para o Programa Saúde da Família (PSF) e o Programa Agentes Comunitários de Saúde (PACS). Diário O ficial da União 2006; 29 mar.

25. Mishima SM, Campos AC. O trabalho no Programa de Saúde da Família - perfil das equipes. Rev Min Enf 2003; 7(2):124-133.

26. Levy, FM, Matos PES, Tomita NE. Programa de agentes comunitários de saúde: a percepção de usuários e trabalhadores da saúde. Cad Saude Publica 2004; 20(Supl. 1):197-203.

27. Silva JA, Dalmaso ASW. Agente Comunitário de Saúde: o ser, o saber, o fazer. Rio de Janeiro: Fiocruz; 2002.

28. Ferraz $L$, Aerts DRGC. 0 cotidiano de trabalho do agente de saúde no PSF em Porto Alegre. Cien Saude Colet 2005; 10(2):347-355.

29. Araújo CT. Confiabilidade do exame bucal realizado por agentes comunitários de saúde no rastreamento de condições, lesões cancerizáveis e câncer bucal no município de Alagoinhas [monografia]. Feira de Santana (BA): Universidade Estadual de Feira de Santana; 2001.

30. Ceccim RB, Feuerwerker LCM. O quadrilátero da formação para a área da saúde: ensino, gestão, atenção e controle social. Physis - Revista de Saúde Coletiva 2004; 14(1):41-65.

Artigo apresentado em 04/06/2007

Aprovado em 13/12/2007 